\title{
Resistance to attitude change as a function of the centrality and relatedness of bonded values*
}

\author{
JOHN D. EDWARDS \\ Ohio State University, Columbus, Ohio 43210
}

Experimentally induced initial attitudes were cognitively bonded to value statements varying on the dimensions of personal importance to Ss and relevance to the attitude object. Neither variable affected the extremity of initial attitude. However, following discrepant information, attitude measures showed that bonding important values to initial attitudes conferred greater resistance to attitude change than either bonding to unimportant values or no bonding. This effect was obtained for both levels of value relevance. Value relevance did not affect resistance to attitude change.

The primary purpose of this experiment was to examine the effects of two properties of values on resistance to attitude change when the values are cognitively bonded to an initial attitude. Based on Ostrom \& Brock's (1968) model, resistance to change was predicted to be a direct function of both value centrality (defined according to ratings of personal importance) and value relatedness (defined according to ratings of the relevance of values to the attitude object).

A second purpose was to determine whether bonding to unimportant, irrelevant values conferred any resistance to change compared to a situation in which no values were bonded. In addition, this experiment permitted an examination of the effects of value importance and relatedness on the extremity of newly formed value-bonded attitudes.

\section{METHOD}

Forty-nine Ss were assigned randomly to five conditions. The independent variables were importance (high vs low) and relevance (high vs low) of the given values The fifth condition was a no-value-bonding control group. The dependent variables were pre- and postdiscrepancy attitude scores and several manipulation checks.

The attitude object was a hypothetical person described by a list of adjectival traits. The initial information about this person was a set of five highly favorable adjectives. 1 After writing a paragraph describing their impressions of the person, Ss wrote a second paragraph describing the relationship they perceived between this impression and one of four sets of values.

*This research was supported by NSF Grant GN-534 to Thomas M. Ostrom. The author wishes to thank Dr. Ostrom for his guidance in every phase of this experiment and A.G. Greenwald for commenting on an earlier draft. Thanks are due also to Eileen Timmerman and Rebecca Edwards for their assistance in data processing.
The mean normative importance rating and the mean normative relatedness index, respectively, of the four value sets are reported in the parentheses: Important-related $(9.68,8.50)$; important-unrelated $(9.19,2.00)$; unimportant-related $(5.37,7.25)$; unimportant-unrelated $(5.36,0.75)$. There were four values in each set. Value importance scale values for each statement were obtained from the ratings of 50 undergraduates (Edwards, 1967a). The present 16 values were selected from a list of 92 value statements which the judges had rated on an 11-point scale whose end points were anchored with the phrases: "very unimportant" (1) and "very important" (11). The value-relatedness score of each value was the number of Ss out of a different sample of 10 Ss who judged the value statement according to its relevance to the process of "forming first impressions." In this procedure, Ss sorted 92 cards, each containing one value statement, into two piles according to whether the idea expressed by the value was relevant or irrelevant to this general issue.

After completing their value-bonding essays, Ss rated the appropriateness of each value in their set to the attitude object on an 11-point scale. The end points of the scale were labeled "low appropriateness" $(0)$ and "high appropriateness" (10). Control Ss did not participate in this value bonding and rating phase. All Ss rated the favorability of their attitudes on an 8-category scale, ranging from favorable to unfavorable, with highly, considerably, moderately, and slightly as modifiers.

Discrepant information was introduced in the form of five additional traits of the person, all of which were slightly negative. ${ }^{2}$ Ss then completed an attitude structure measure (Edwards \& Ostrom, 1969) that was used to assess their final attitudes. On this instrument, Ss indicated how certain they were that the target person possessed or did not possess 18 other traits which had not appeared before in the experiment. These traits ranged from very favorable adjectives (e.g., truthful) to very unfavorable adjectives (e.g., malicious) and were approximately equally spaced across the favorability dimension. These certainty ratings were used (1) to form a single-score measure of attitude and (2) to examine differences in belief certainty as a function of the evaluative level of the traits.

After completing this instrument, Ss responded to five questions designed to examine further the effects of the manipulations. The questions asked how confident the Ss were that their initial impressions of the target person was accurate and unchangeable, what effect the value-bonding task had on their confidence in their first impressions, how consistent the values were with their initial impressions, the relative favorability of the two sets of information, and what effect the value-bonding task had on the favorability of their initial impressions. Finally, all Ss were asked to write down any thoughts that occurred to them during the experiment.

\section{RESULTS AND DISCUSSION}

Postbonding, Prediscrepancy Attitude

Value importance and relatedness had no effect on the extremity of initial attitudes as indicated by the favorability rating scale (all $\mathrm{ps}>.25$ ). In all five conditions, the mean initial attitude most closely corresponded to the category label, "considerably favorable." The high-importance condition produced a slightly more extreme attitude (1.85) than the low-importance condition (2.05), but a less extreme attitude than the control group (1.56).

Postdiscrepancy Attitude

Based on the notion that a person's attitude can be defined as the average favorability of the beliefs about the attitude object which a person endorses (Thurstone, 1928), an index of final attitude was derived from the attitude structure measure by calculating the mean

Table 1

Postdiscrepancy Attitude Scores Derived from the Attitude Structure Measure as a Function of Value Importance and Relatedness

\begin{tabular}{cccc}
\hline & \multicolumn{2}{c}{ Importance } \\
\cline { 2 - 3 } & High & Low \\
\hline \multirow{2}{*}{ Relatedness } & High & $4.90(10)$ & $4.27(10)$ \\
\cline { 2 - 3 } No Value Bonding Control & Low & $4.65(10)$ & $4.01(10)$ \\
\hline
\end{tabular}

Note-Sample sizes are given in parentheses. The higher the mean, the more favorable the attitude. The range of possible scores was 1.22 to 6.61 


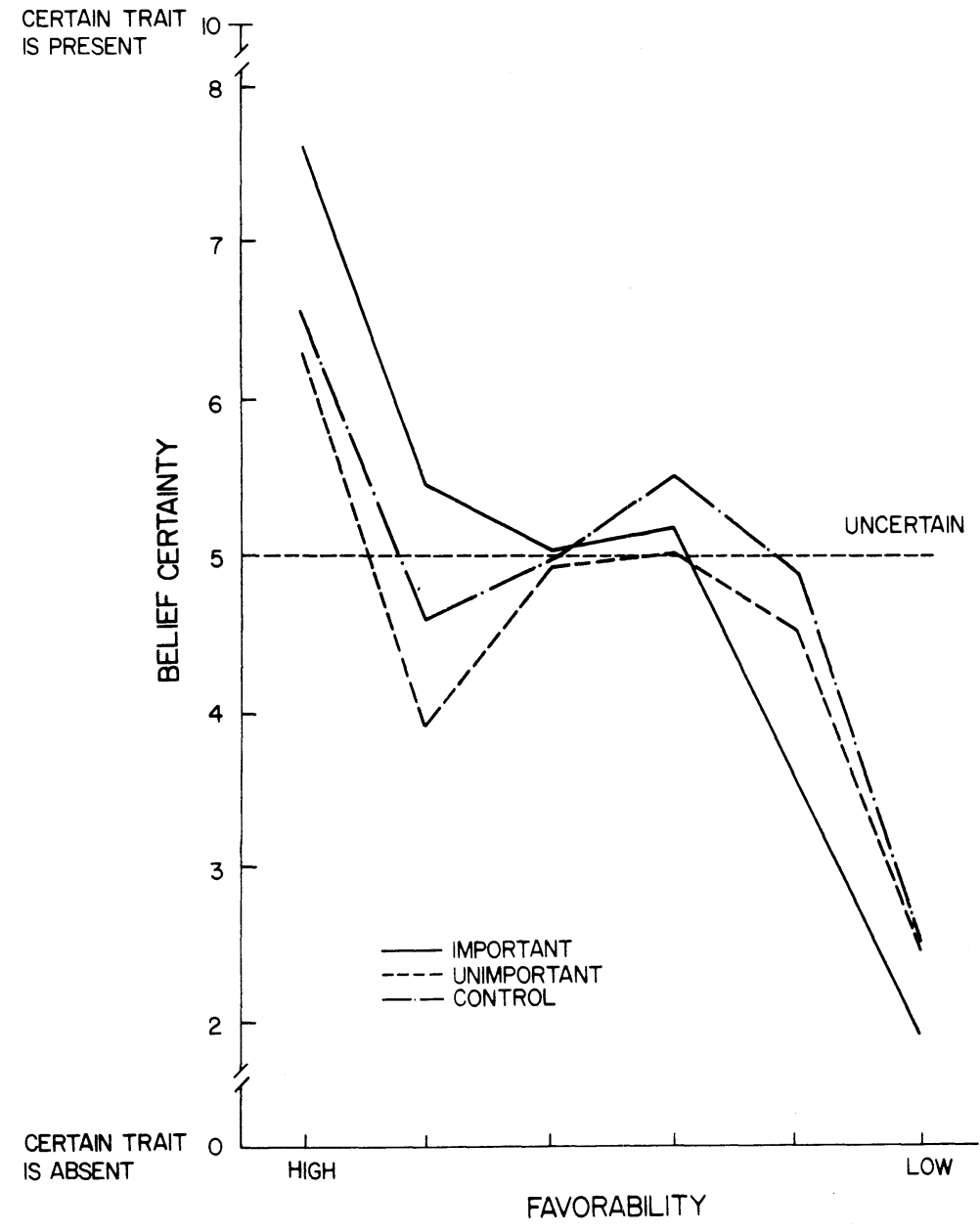

favorability of the adjectives that received a certainty rating of six or greater. Responses in this range indicated that Ss believed that the target person possessed those traits so rated. The mean attitude scores using this measure are given in Table 1. Analysis of variance of the four value-bonding conditions indicated that $\mathrm{Ss}$ in the important value condition had a significantly more favorable attitude than $\mathrm{Ss}$ in the unimportant condition $(\mathrm{F}=5.53$, $\mathrm{df}=1 / 36, \quad \mathrm{p}<.024)$. This difference occurred under both high and low relatedness. The main effect of manipulated relevance and the interaction were not significant (both ps $>.35$ ). The mean of the control group differed from the important value condition $(\mathrm{t}=1.60$, $\mathrm{df}=27, \quad \mathrm{p}<.07)$, but not from the unimportant value condition $(\mathrm{t}=.46$, $\mathrm{df}=27, \mathrm{p}>.30$ ).

To examine the effects of value bonding on attitude structure, the 18 adjectives were combined into six groups of three traits each. The groups were formed on the basis of normative favorability and ranged from containing the three most favorable traits to containing the three least favorable traits. Six scores were obtained for each $\mathrm{S}$ by computing the mean certainty rating given for the three traits within each group. Analysis of variance of these certainty data with favorability groups as a within-Ss factor produced a nearly significant Importance by Groups interaction $(\mathrm{F}=2.25, \quad \mathrm{df}=5 / 180$, $\mathrm{p}<.053)$. This interaction is shown in Fig. 1 along with the control group data. This graph indicates that $S s$ in the important-value condition were more certain about the presence of favorable traits and more certain about the absence of unfavorable traits than were $S$ s in the unimportant-value condition. This result, coupled with the single-score data reported above, indicates that the $S s$ in the important-value condition retained their initially favorable attitude to a significantly greater degree than $\mathrm{Ss}$ in the unimportant-value condition. The belief-certainty profile of the control group was more similar to that of the unimportant-value condition than to that of the important-value group. Except for the main effect of favorability groups $(\mathrm{F}=21.83, \mathrm{df}=5 / 180, \mathrm{p}<.001)$, no other
Fig. 1. Belief certainty as a function of trait favorability in the important and unimportant value conditions and in the control condition.

effects in the certainty data analysis were significant.

Additional Analyses

Immediately after the value-bonding task, Ss rated the appropriateness of each value to the attitude object. Important values were rated as more appropriate than were unimportant values $(\mathrm{F}=8.96$ $\mathrm{df}=1 / 36, \quad \mathrm{p}<.005)$. However, related values were not rated as more appropriate than unrelated values. Apparently, the normative relatedness scaling procedure was deficient in that it did not produce value sets which were differentially related to the present attitude object. When these appropriateness ratings were used as a covariate in a reanalysis of the postdiscrepancy attitude scores, the significant importance main effect was attenuated $(F=3.32, \mathrm{df}=1 / 35, \mathrm{p}<.077)$.

Of the five postexperimental questions, the only one showing any significant effects was the question asking Ss to indicate how accurate and unchangeable their initial impression was. Important-value $\mathrm{Ss}$ indicated greater devotion to their first impression than did unimportant-value $\mathrm{Ss}(\mathrm{F}=4.99, \mathrm{df}=1 / 36$, $\mathrm{p}<.031)$. This finding is consistent with the attitude change data reported above.

\section{CONCLUSIONS}

These results extend earlier findings (Edwards \& Ostrom, 1969) that the cognitive bonding of important values does not affect the level of initial attitudes but does enhance resistance to attitude change. Bonding of unimportant values confers no more resistance than no bonding. The effects of value importance were similar under both high and low levels of normative relatedness. Although the predicted effects of relatedness were not obtained, manipulation checks suggested that the present manipulation was unsuccessful. Apparently, the normative relatedness ratings with regard to a general attitude issue were inadequate for producing the required perception of relevance to the specific attitude object. The body of research on the value-bonding model tentatively suggests that resistance to persuasion might be bolstered by making value-attitude bonds salient if the values are important. One of the present findings suggests that value-bonding effects may operate in part by increasing one's confidence in the accuracy of one's initial attitudinal position. 


\section{REFERENCES}

EDWARDS, J. D. An ordered list of values: Its derivation and utility. Ohio State University (mimeo), 1967a.

EDWARDS, J. D. Revised likeableness ratings of 554 personality trait adjectives. Ohio State University (mimeo), 1967b.

EDWARDS, J. D., \& OSTROM, T. M. Value bonded attitudes: Changes in attitude structure as a function of value bonding and type of communication discrepancy. Proceedings of the 77th Annual Convention of the American Psychological Association, 1969, 413-414.

OSTROM, T. M., \& BROCK, T. C. A cognitive bonding model of attitudinal involvement. In R. P. Abelson et al (Eds.), Theories of cognitive consistency: A sourcebook. Chicago: Rand McNally, 1968. Pp. 373-383.

THURSTONE, L. L. Attitudes can be measured. American Journal of Sociology, 1928, 33 529-554.

NOTES

1. The five initial traits and their favorability scale values (Edwards, 1967b) were: friendly (6.55), interesting (6.14), loyal (6.54), sincere (6.62), and warm-hearted (6.30).

2. The five discrepant traits and their favorability scale values (Edwards, 1967b) were nonconfident (3.02), tense (3.03), unoriginal (3.03), preoccupied (3.19), and inexperienced (3.60).

\section{Bilinguals as linguistic mediators*}

\section{G. RICHARD TUCKER and HELEN GEDALOF McGill University, Montreal, P.Q., Canada}

A variation of the standard word-association technique, together with the cloze procedure, was used to explore whether balanced bilinguals of French Canadian parentage could communicate equally well with monoligual English or French speakers. The bilingual Ss clozed significantly better with the French Ss than with the English. These results suggest that distinctive French Canadian cultural values and traditions may have influenced their ability to communicate with peers. The individual who appears to be equally proficient in two or more languages may really not be an effective linguistic mediator.

The topic of intergroup communication is especially interesting to those of us who live and work in such linguistically diverse areas as Montreal. The anecdotal observations and research conducted by anthropologists and sociologists (e.g., Allen, 1955; Christian, 1970; Nostrand, 1966) suggest that an individual's values and traditions filter or bias, in some way, his transmission or reception of information. That is, their evidence, which they interpret as support for a theory of cultural relativism, implies that failures to communicate may result when two people who share a common vocabulary do not share similar cultural frames of reference. We have recently begun to explore empirically one aspect of the relationship between bilingualism and biculturalism, namely, whether or not apparently "balanced" bilinguals can communicate equally well with native speakers from both of their reference groups.

In our setting, this hypothesis may be tested by seeing whether French-English bilinguals of French parentage communicate equally well with both monolingual French and monolingual

\footnotetext{
*This research was supported by grants from the Canada Council, Defense Research Board, and the French Canada Studies Programme to W. E. Lambert and G. R. Tucker.
}

English speakers or whether they communicate better with the French group. We have used a variation of the standard word-association technique together with the cloze procedure to test this hypothesis.

The free-association technique has been extensively used to study verbal behavior. Following the standard procedure, a $\mathrm{S}$ is presented with a number of words and asked to respond to each stimulus word, orally or in writing, with the first word that comes to mind. Through force of tradition, most research has been conducted using the familiar Kent-Rosanoff stimulus list. Normative studies have now been conducted in several western countries, and bases for between-group comparisons have been established (e.g., Jenkins \& Russell, 1960; Palermo \& Jenkins, 1964; Rosenzweig, 1961).

More recently, and of particular relevance to the present study, Lambert \& Moore (1966) used this technique to compare the responses given by Canadian bilinguals with Canadian English and French monolinguals. They reported that the bilinguals responded like the English monolinguals on the English form of the test, and like the French monolinguals on the French form. They hypothesized that the associational responses define
" "particular connotative meaning networks," and suggested that group differences in associational correspondence may determine the difficulty or ease of communication both within and across linguistic groups.

Gotlieb (1967) collected word-association responses and short compositions from a group of male high school students. He then calculated the number of similar responses (overlap) given by all combinations of students taken two at a time, and selected, for each $\mathrm{S}$, one student with whom he had high overlap and another with whom he had low overlap. He gave each $S$ the two compositions written by the high-overlap and low-overlap students with every fifth word deleted, and asked them to fill in the blanks. This technique, known as the "cloze procedure" (Taylor, 1959), measures the readability of a written passage. In this case, Gotlieb found that male high school students could comprehend better passages written by peers with whom they had high associational correspondence than those written by peers with whom they had low overlap.

The present study was designed to explore directly one aspect of the relationship between associational similarity and intergroup communication, and, indirectly, one aspect of the relationship between bilingualism and biculturalism using Gotlieb's methodology. The previous data suggest two equally plausible outcomes. One could argue that a linguistically balanced bilingual with French-Canadian parents should cloze equally well with either English or French high-overlap peers and that this clozure would be better than that with low-overlap peers, or that such a person who appears from all surface indications to be a balanced bilingual should, in fact, cloze significantly better with French peers, regardless of overlap, than with English peers.

\section{SUBJECTS}

The Ss were 10 male and 10 female Grade 9 students from middle-class homes in Montreal. All had French-Canadian parents and appeared to be balanced bilinguals. The criteria for bilinguality were adopted from Lambert \& Moore (1966) and Macnamara (1969). In addition, one large group of English-Canadian monolingual students and another of French-Canadian monolinguals, comparable in age, religion, and socioeconomic status, were selected for the preliminary phase of the study from the high streams in their respective schools. MATERIALS

Fifty of the 100 words from the 